\title{
Multiculture Development on New Media Platform
}

\author{
Xiao Han ${ }^{*}$ \\ ${ }^{1}$ Faculty of Design Science, The University of Sydney \\ *Corresponding author. Email: hx8617@gmail.com
}

\begin{abstract}
Nowadays, with the development of the public transport system, the population movement becomes much more quickly. When immigrants start to live in a new place who need to adapt to the new cultural environment and bring a new culture to the local community, even in recent years, due to the spread of Covid -19 , people have to stay at home and cannot travel across regions as before. The integration and development of multiculturalism have never stopped. The spread of multiculturalism, especially on new media platforms, is even faster than before. It is foreseeable that in the future, with the acceleration of global integration, cultural diversity and cultural integration and media globalization will be an unstoppable trend. This article introduces the basic cognition and definition of multiculturalism and reveals the shortcomings of multicultural research at this stage. More importantly, this paper demonstrates how multiculturalism can be spread on new media platforms from different fields, including economy, technology, culture and education, society. Finally, it is concluded that multiculturalism depends on the dissemination of new media platforms and promotes the development of new media platforms. This article aims to prove that the product of multiculturalism on new media platforms is conducive to the rise of the social economy and globalization.
\end{abstract}

Keywords: multiculture, new media, communication, Australia

\section{INTRODUCTION}

In the spring of 1988, a curriculum reform on the campus of Stanford University in the United States became the beginning of the later "cultural revolution". Since the 1990s, an important cultural phenomenon appeared in American society, including ideology, education and politics. Throughout the 1990s, 1 million new immigrants poured into the United States annually, and recent immigrants brought the culture from their hometown into the United States[1]. This is mainly reflected in language, food, and other details relates to daily life. With the increase in the number of immigrants, ethnic minorities have formed an enormous group, and their population has continued to increase. To integrate into the local society and development better, they constantly try to fight and integrate with the mainstream culture. These first immigrants contributed immense strength to the origin of multiculturalism. In Australia, multiculturalism is a concept and policy designed to deal with the increasing ethnic and cultural diversity of Australian society caused by large-scale immigration in the decades after World War II, and the immigration policy of abandoning racial restrictions in the 1960s by overcoming Limitations of previous methods of assimilation and integration[2]. In China, multiculturalism refers to the acceleration of cultural renewal and development as human society is becoming more and more complex and information dissemination more and more abundant. Cultural development still faces challenges. According to relevant documents, the definition of multiculturalism varies with different backgrounds. All descriptions have the same understanding of multiculturalism. the formation depends on the exchange and integration of information.

\section{THE SHORTCOMINGS OF MULTICULTURAL COMMUNICATION RESEARCH}

Due to the different national conditions of each country, the degree of research on multiculturalism is also very different. For those immigrant countries, such as the United States, Canada, and Australia, multicultural research is relatively mature. From 2004 to 2005, a total of 123,424 people immigrated to Australia. Among them, 17,736 were from Africa, 54,804 were from Asia, 21,131 were from overseas, 18,220 were from the United Kingdom, 1506 were from South 
America, and 2,369 were from Eastern Europe[3].New South Wales is the most multiculture state and also has the highest proportion of the foreign-born population. According to the 2006 census, there are 1,544,023 people born locally. $74.5 \%$ comes from Lebanon, and $63.1 \%$ comes from Italy, $63 \%$ comes from South Korea, $59.4 \%$ comes from Fiji, and $59.4 \%$ comes from China[4]. Even if the local government continued implementing international travel, the Australian immigrant population still occupies a certain proportion of the total population growth. Many immigrants bring multiculturalism to Australia and drive Australia to attach importance to the development of multiculturalism. As one of the most successful multicultural societies globally, the Australian society system has a multicultural department, encourages the development of local media in different languages, and regularly organizes multicultural communication events. Government and the press cooperate to promote cultural integration and development. Of course, in some countries, the situation is just the opposite. An important reason is the relatively simple population composition and local policies, such as North Korea. Affected by the lock-up policy, North Korea has almost cut off all domestic and foreign satellite broadcast signals, especially TV signals from Japan and South Korea. Commercial advertisements are also rare.

Another reason that interferes with the development of multiculturalism is discrimination. There are two main reasons cause it: preference and information asymmetry[5]. Due to the lack of cultural background, some locals don't like to contact cultures they are not familiar with. Some people even think that the invasion of foreign culture has eroded the local culture and compressed the development space of the local culture. They tend to spend more time and money on the local culture they are familiar with and love. In more closed areas, locals are even resistant to immigrants. They believe that immigrants compete with them for local resources and job opportunities. To reduce the pressure of competition, they directly refuse to release all other cultures.

The third reason hindering the development of multiculturalism is the limitation of people's understanding of it. Many people think that multiculturalism only involves cultural exchanges and integration and depends on the media. Multiculturalism is an ideology that unconsciously affects people's daily lives, such as economy, technology, creativity, education, and social stability.

\section{THE VALUE OF APPLYING NEW MEDIA TO DEVELOP MULTICULTURE}

\subsection{Economy}

\subsubsection{Commercial promotion}

The media is a tool for exchanging information. Due to the development of technology, the emerging communication tool is the new media. There are four traditional media for communication, including newspapers, magazines, television and radio. The Internet provides a new media platform. In recent years, there have also been Internet derivative products, such as commercial websites, Weibo, WeChat, YouTubes, TikTok and other social media. The emergence of new media has improved the efficiency of multicultural communication and extensively promoted economic development. The emergence of new media has improved the efficiency of multicuture communication so has greatly promoted economic development.

Firstly, in an immigration country or multiculturalism area, businesses want to get people from different cultural backgrounds to recognize and buy their products. With the development of new media, manufacturers can realise the features and needs of different cultures as exhaustive as possible and then design advertisements and online promotion events for other groups of people.

In Australia, 20.8\% of people spoke a language other than English at home in 2016[6]. Because of language barriers, many new immigrants do not often watch or listen to the mainstream traditional Australian media, resulting in advertisements that these ethnic minority groups cannot manage. However, even if they do not watch TV or listen to the radio, these new immigrants still have approaches to get information, such as a new media platform, such as YouTube. Therefore, to promote products to more audiences, businesses regularly place targeted advertisements on YouTube. For example, if you are a Chinese language user or watch a Chinese program, a Chinese advertisement for tens of seconds will pop out automatically at the beginning of each program. More detailly speaking, businesses can determine the age, gender, and preferences of viewers based on the programs they choose. For example, if you are a Chinese user and often watch investment programs, the advertisement of a Chinese investment company will be automatically played at the beginning of the video. Use new media platforms to place such multicultural advertisements accurately. This can reduce the promotion cost of enterprises and promote the development of local enterprises as much as possible. 


\subsubsection{Product creativity}

With the prosperity of the new media platform and digital marketing, the distance between products and consumers has narrowed. Products' contents can be driven by customers. They can customize their products based on their own cultural needs, and businesses can also get market feedback as soon as possible. For example, printing, a startup from Riga, Latvia, offers over 300 products such as t-shirts, mugs, socks, and home accessories ready for you to customize[7]. Customers can choose the product they like and design it online. Then they can preview the products on highquality images. If customers are satisfied with their design, the products will be shipped directly to them. Also, they can sell their designed products efficiently online.

Due to the convenient communication and the diverse cultural background, various ideas emerge in products endlessly. So developing multiculturalism in new media platforms will increase interaction with consumers significantly and enhance product creativity, and at the same time drives the market.

\subsection{Technology innovation}

\subsubsection{Talent competition}

With the emergence of social media platforms, diversified new media methods and self-media are welcomed, which lowering the barriers to access new technologies and new products. Some science technologies were hard to understand in the past. Still, new media platforms, such as forums, short videos, and live broadcasts, allowing the audience to learn about new technologies from multiple angle. Everyone can express their opinions and participate in them. At the same time, it attractive brilliant people from different backgrounds and industries to participate in technology innovation, which significantly improved participation and competitiveness to bring the wisdom from more people to trigger science and technology innovation.

\subsubsection{Product upgrading}

Technology has digitized media content, and whether it is text or pictures, sound or video, all have been digitized and loaded into portable devices. People can get the latest information online anytime, anywhere. This has also led to higher and higher requirements for mobile terminal electrical products. For example, in the early 21st century, people's needs for mobile phones were to answer calls and send text messages. However, in recent years, mobile phones are no longer limited to communication devices. They are also intermediary of new media platforms. Consumers require it to take pictures, upload videos, play videos clearly, and so on. Especially in a multicultural society, mobile phones play essential roles in getting or translating information more conveniently. This requires mobile phones to be constantly updated to meet the needs of consumers.

\subsection{Culture and education}

\subsubsection{Cultural Globalization}

Because of the high efficiency of new media, everyone can express their opinions, and everyone has a better understanding and integration of themselves and the world, which also promotes popularization. Videos can be placed on various platforms in different formats, such as Facebook, Instagram, Weibo, WeChat and Tiktok. The audience can understand the culture from different angles. For example, we can easily understand the life of "African tribal life" without leaving home, and there are even bloggers who imitate their lives in pursuit of high click-through rates. In the process of watching and discussing, we unknowingly broadened our horizons and increased our cultural heritage. Such a phenomenon is conducive to enhance the inclusiveness of global culture and is also conducive to the inheritance of traditional culture.

\subsubsection{Multiculture Education}

Multiculture education refers to any form of education or teaching that incorporates the histories, texts, values, beliefs, and perspectives of people from different cultural backgrounds[8]. Multicultural education gives students opportunities to build understanding and communication skills across cultures. Dr. Anders Ericsson believes genius is the product of training. Some abilities can only be developed before the age of 6,12 , or 18 , or it is easier to develop before these ages[9]. Develop multicultural education to provide more choices for children. For example, a child who has received bilingual education from an early age will have more developed language talents than others. In addition, with bilingual ability, he can access more information quickly in the future.

\subsection{Society}

\subsubsection{Promote social stability}

The spread of multiculturalism on new media platforms plays an essential role in the social stability of immigrant countries. For example, Australia has 100 religions and more than 300 different ethnic groups[10]. With so many ethnic groups and cultures, if multiculturalism is not promoted, it is easy to cause conflicts in our society and cause ethnic and regional conflicts worldwide. In the early years, Australia's longterm monocultural policy caused disputes between different ethnic groups, which was highly detrimental to the country's stability. Therefore, unity among nations is 
the foundation for national and social security and stability.

\subsubsection{Increase employment opportunities}

In recent years, society has increasingly demanded talents who understand new media and multi-culture. Many Australian Chinese can feel that their social status in Australia is gradually improving. Compared with 20 years ago, most Chinese people prefer to open "Chinese restaurants", until now Chinese people have worked in all industries. Moreover, Aussie companies also hope to absorb employees from diverse backgrounds to enrich the company's culture and broaden overseas markets. At the same time, we can also see on SEEK website that many job positions are only open to aboriginals or bilingual users. Job demand drives the demand for education. In recent years, various schools have opened multiculture courses, which shows that multiculturalism in Australia is gradually increasing.

\section{CONCLUSION}

New media and multiculturalism complement each other. New media has promoted the development of multiculturalism. On the contrary, multiculturalism has also announced the prosperity of new media. Also, as a creature of age, the two have a significant side: strong tolerance. This research discusses the importance of combining the two from the four aspects: economy, technology, culture, and social development. In the future, if the two can be mixed and applied in reality, human society will be highly possible to further developed, which is also in line with the process of globalisation.

\section{REFERENCES}

[1] Wenku.baidu.com. 2021. Research on the Origin of American Multiculturalism. [online] Available at:https://wenku.baidu.com/view/8901426ca6c30c2 259019e8f.html?fixfr=Us\%252FZHgFLQd8EtbBm MKky8A\%253D\%253D\&fr=income1-

wk_go_search-search

[2] Department of Immigration and Citizenship (DIAC), 'Abolition of the 'White Australia Policy", Fact Sheet no.8, DIAC, Canberra, 10 September 2009, viewed 5 October 2010, http://www.immi.gov.au/media/factsheets/08abolition.htm

[3] Australian Bureau of Statistics. 2021. Migration, Australia, 2019-20 financial year. [online] Available at: https://www.abs.gov.au/statistics/people/population /migration-australia/latest-release
[4] Abs.gov.au. 2021. 2006 Census data. [online] Available at: https://www.abs.gov.au/websitedbs/censushome.ns f/home/historicaldata2006?opendocument\&navpos $=280$

[5] Xue zhao feng, 2018. Xue zhao feng Economics lectures. Beijing: Zhong xin chu ban ji tuan gu fen you xian gong si.

[6] Abs.gov.au. 2017. Census reveals a fast changing, culturally diverse nation. [online] Available at: https://www.abs.gov.au/ausstats/abs@.nsf/lookup/ media\%20release 3

[7] Printify. 2021. Printify Drop Shipping \& Printing Service for E-commerce. [online] Available at: https://printify.com/

[8] The Glossary of Education Reform. 2021. Multicultural Education Definition. [online] Available at:https://www.edglossary.org/multiculturaleducation/

[9] Ericsson, A. and Pool, R., n.d. Summary of Peak : secrets from the new science of expertise by Anders Ericsson and Robert Pool.

[10] Eccv.org.au. 2021. [online] Available at: https://eccv.org.au/wpcontent/uploads/2018/03/Census2016_JUNE28201 7.pdf 